\title{
GRAIN GROWTH AND PHASE MORPHOLOGY IN ION BEAM MIXED, TWO PHASE Ni-Al AND Ni-Cr-Al ALLOYS
}

\author{
Dale ALEXANDER ${ }^{1)}$, Gary WAS ${ }^{1)}$ and James ERIDON ${ }^{2)}$ \\ "University of Michigan, Department of Nuclear Engineering, Ann Arbor, Michigan 48109, USA \\ 2) Naval Research Iaboratory, Surface Modifications Branch, Washington, DC 20375, USA
}

\begin{abstract}
Multilayers of $\mathrm{Ni}-21 \mathrm{Al}$ and $\mathrm{Ni}-20 \mathrm{Cr}-10 \mathrm{Al}$ were subjected to ion beam mixing using $350 \mathrm{keV} \mathrm{Ni}{ }^{+}$ions and/or thermal annealing at $440^{\circ} \mathrm{C}$ to study the development of grain growth and phase morphology. Two film thicknesses of $\mathrm{Ni}-21 \mathrm{Al}(60$ and 120 $\mathrm{nm}$ ) were investigated. Both thermal annealing and irradiation resulted in grain growth in the $\mathrm{Ni}-21 \mathrm{Al}$ samples. Grain size increased by a factor of 7 after irradiation and only 3-4 after annealing. Annealing produced a two phase $\gamma+\gamma^{\prime}$ structure and nonuniform grain sizes while the irradiation produced a supersaturated solid solution with more uniform grain size. Annealing subsequent to irradiation produced a structure consisting of $\gamma+\gamma^{\prime}$ and an HCP phase. There was no difference in grain growth behavior as a function of film thickness. The $\mathrm{Ni}-\mathrm{Cr}-\mathrm{Al}$ film exhibited no grain growth during annealing and only a factor of 6 increase during irradiation. Irradiation alone or post-irradiation annealing produced nearly identical structures of $\gamma$ and the HCP phase. The $\gamma^{\prime}$ phase was never observed in the $\mathrm{Ni}-\mathrm{Cr}-\mathrm{Al}$ film. All irradiated samples showed a more uniform grain size compared to that following annealing. Considerable texture was observed in all irradiated samples in which the gamma grains in the film were aligned with the Ni grains in the substrate.
\end{abstract}

\section{Introduction}

Previous work [1] has shown that ion beam mixing of $\mathrm{Ni}-\mathrm{Al}$ results in significant grain growth along with the formation of a unique dual phase gamma-gamma prime structure. This structure was shown to be stable against decomposition and grain growth during elevated temperature anneals for extended periods. However, little is known about the effects of ion energy, ion dose or annealing temperature on the formation and stability of the dual phase structure.

The present work addresses the effect of initial film thickness on ion induced grain growth and formation of the dual phase structure with composition Ni-21Al. This work also examines the effects of $\mathrm{Cr}$ on the formation of the dual phase structure. The $\mathrm{Ni}-\mathrm{Cr}-\mathrm{Al}$ system forms the basis of many of the high temperature, high strength superalloys, and thus ion beam mixing in this system may produce unique nonequilibrium microstructures with enhanced high temperature stability.

\section{Experimental}

Samples were preparcd using $3 \mathrm{~mm}$ diameter disks punched from $0.25 \mathrm{~mm}$ thick, $99.998 \%$ pure nickel foil. The disks were annealed in an argon atmosphere at $1273 \mathrm{~K}$ for $4 \mathrm{~h}$. The surfaces of the disks were successively polished with 600 grit $\mathrm{SiC}$, alumina slurry, and
Syton ${ }^{\infty}$. A short jet electropolish of the surface was provided as a final finish.

Evaporations were performed to provide three sets of samples with different compositions and thicknesses: $60 \mathrm{~nm}$ of $\mathrm{Ni}-21$ at.\% Al, $120 \mathrm{~nm}$ of Ni-21Al, and 60 $\mathrm{nm}$ of $\mathrm{Ni}-20 \mathrm{Cr}-10 \mathrm{Al}$. Multilayers were deposited on the $\mathrm{Ni}$ disks by electron beam evaporation in a vacuum system with base pressure $<2 \times 10^{-7}$ Torr. The layer thicknesses were adjusted to provide the target surface compositions. The thickest layers did not exceed $6 \mathrm{~nm}$. The evaporation rate typically varied between $0.1-0.5$ $\mathrm{nm} / \mathrm{s}$. Rutherford backscattering analysis was performed on the $60 \mathrm{~nm}$ and $120 \mathrm{~nm} \mathrm{Ni}-\mathrm{Al}$ samples to verify the film composition.

Ion beam mixing of the layered structures was conducted in a Varian Extrion ion implanter at the Michigan Ion Beam Laboratory for Surface Modification and Analysis. Samples were irradiated at room temperature with $350 \mathrm{keV}^{58} \mathrm{Ni}^{+}$to a dose of $4 \times 10^{16}$ ions $/ \mathrm{cm}^{2}$. The dose rate was typically $4.4 \times 10^{12}$ ions $/ \mathrm{cm}^{2} \mathrm{~s}$. This dose was chosen to achieve the same surface displacement damage (about $70 \mathrm{dpa}$ as determined by TRIM [2]) produced in previous work with $500 \mathrm{keV} \mathrm{Kr}^{+}$ions [1]. The vacuum in the diffusion pumped end station during irradiation was nominally in the upper $10^{-7}$ Torr range. The temperature of the samples was monitored during irradiation by a thermocouple attached to the disk holder. The increase in the monitored temperature was no greater than $10 \mathrm{~K}$. 
Both irradiated and unirradiated samples were annealed for 1 hour at $710 \mathrm{~K}$ in a cryopumped, stainless steel chamber. During the anneal the pressure in the system did not exceed $1 \times 10^{-6}$ Torr. Following both irradiation and annealing, the disks were prepared for transmission electron microscopy (TEM). A protective lacquer was applied to the modified surface, and the disks were back-thinned in a jet electropolisher with a chilled solution $(220 \mathrm{~K})$ of $20 \%$ perchloric acid, $80 \%$ ethanol. The modified surface structures were studied using both bright and dark field imaging together with selected area diffraction (SAD) in a JEOL 2000FX scanning transmission electron microscope.

\section{Results and discussion}

Dark field imaging, using reflections from the (220) ring, was used to isolate grains and facilitate measurement of the average grain size for each of the treatments studied. Table 1 summarizes the average grain size of the three surface films investigated as a function of the surface treatment. Figs. 1 and 2 show the dark field images of grains resulting from the various treatments on the $120 \mathrm{~nm} \mathrm{Ni}-\mathrm{Al}$ and $60 \mathrm{~nm} \mathrm{Ni-Cr}-\mathrm{Al}$ samples, respectively. Because the (220) ring used for the dark field imaging is common to both the $\gamma$ and $\gamma^{\prime}$ phases, the grains imaged in these figures could correspond to either phase. In the as-evaporated case, all three types of films exhibited a microstructure consisting of every fine, equiaxed grains, $8 \mathrm{~nm}$ in size.

The vacuum anneal at $710 \mathrm{~K}$ for $1 \mathrm{~h}$ produced grain growth to $35 \mathrm{~nm}$ and $21 \mathrm{~nm}$ in the $60 \mathrm{~nm}$ and $120 \mathrm{~nm}$ $\mathrm{Ni}-\mathrm{Al}$ films, respectively. Fig. 1a shows a dark field image of the resulting grain structure in the $120 \mathrm{~nm}$ annealed sample in which nonuniform grain growth has occurred during annealing. No growth was observed in the annealed $\mathrm{Ni}-\mathrm{Cr}-\mathrm{Al}$ multilayers. The observance of grain growth in the annealed $\mathrm{Ni}-\mathrm{Al}$ samples is in contrast to results of previous work in the $\mathrm{Ni}-\mathrm{Al}$ system by Eridon et al. [1] who observed no grain growth after a similar annealing treatment. The only apparent difference between this work and Eridon's is that they used individual layer thicknesses approximately twice those used in this work. However, our results are not inconsistent with observations by Hentzell et al. [3] on the grain growth in $\mathrm{Ni}-\mathrm{Al}$ films co-deposited onto substrates held at high temperature. Also, work by Liu et al. [4] on thin Ni films demonstrated nonuniform grain growth even after shorter, lower temperature anneals than were performed in this work.

Substantial ion beam induced grain growth was observed in all samples irradiated with $350 \mathrm{keV} \mathrm{Ni}^{+}$to a dose of $4 \times 10^{16}$ ions $/ \mathrm{cm}^{2}$. Grain sizes averaged 61,58 , and $46 \mathrm{~nm}$ for the $60 \mathrm{~nm} \mathrm{Ni-Al}, 120 \mathrm{~nm} \mathrm{Ni}-\mathrm{Al}$, and 60 $\mathrm{nm} \mathrm{Ni}-\mathrm{Cr}-\mathrm{Al}$ films, respectively. Unlike annealing, irradiation produced more uniform grain growth. The growth observed was of the same magnitude reported for $\mathrm{Kr}^{+}$irradiation of $\mathrm{Ni}-\mathrm{Al}$ multilayer films [1] and irradiation of Ni films [4].

Post-irradiation annealing produced minimal additional grain growth. Thus the ultimate grain sizes achieved were 74, 64, and $52 \mathrm{~nm}$ for the $60 \mathrm{~nm} \mathrm{Ni}-\mathrm{Al}$, $120 \mathrm{~nm} \mathrm{Ni}-\mathrm{Al}$ and $60 \mathrm{~nm} \mathrm{Ni-Cr}-\mathrm{Al}$ samples, respectively. The lack of a large difference in ultimate grain size in the $60 \mathrm{~nm}$ and $120 \mathrm{~nm} \mathrm{Ni-Al} \mathrm{films} \mathrm{is} \mathrm{significant}$ because it has been shown [5-7] that film thickness effects such as thermal grooving [8] can limit grain growth to a size which is a multiple of the film thickness. It is thus apparent that film thickness effects are not limiting grain growth in this case. The effect of dose on grain growth has not been specifically addressed, however, Liu et al. [4] demonstrated that saturation grain sizes are achieved in irradiated $\mathrm{Ni}$ films at doses approaching $1 \times 10^{16}$ ions $/ \mathrm{cm}^{2}$. Since our dose was considerably higher than this, the observed grain sizes may well be at the saturated value.

Analysis of the phases present after surface treatment was conducted using selected area diffraction (SAD). Patterns for the $120 \mathrm{~nm} \mathrm{Ni-Al} \mathrm{and} 60 \mathrm{~nm}$ $\mathrm{Ni}-\mathrm{Cr}-\mathrm{Al}$ samples are shown in figs. $\mathrm{l}$ and 2 respectively, and a tabulation of all phases observed is included in table 1. Examination of the annealed $120 \mathrm{~nm}$ sample, fig. 1a, shows that in addition to the $\gamma$ phase, superlattice rings belonging to the ordered $\gamma^{\prime}$ prime phase are present. These are the equilibrium phases predicted by the binary phase diagram for the composition $\mathrm{Ni}-21 \mathrm{Al}$.

Table 1

Summary of average grain size (in $\mathrm{nm}$ ) and observed phases for various surface treatments

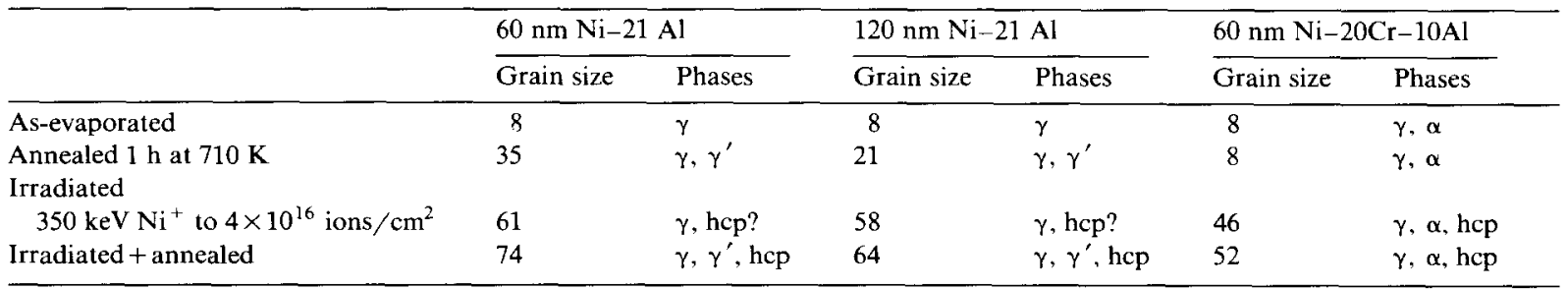




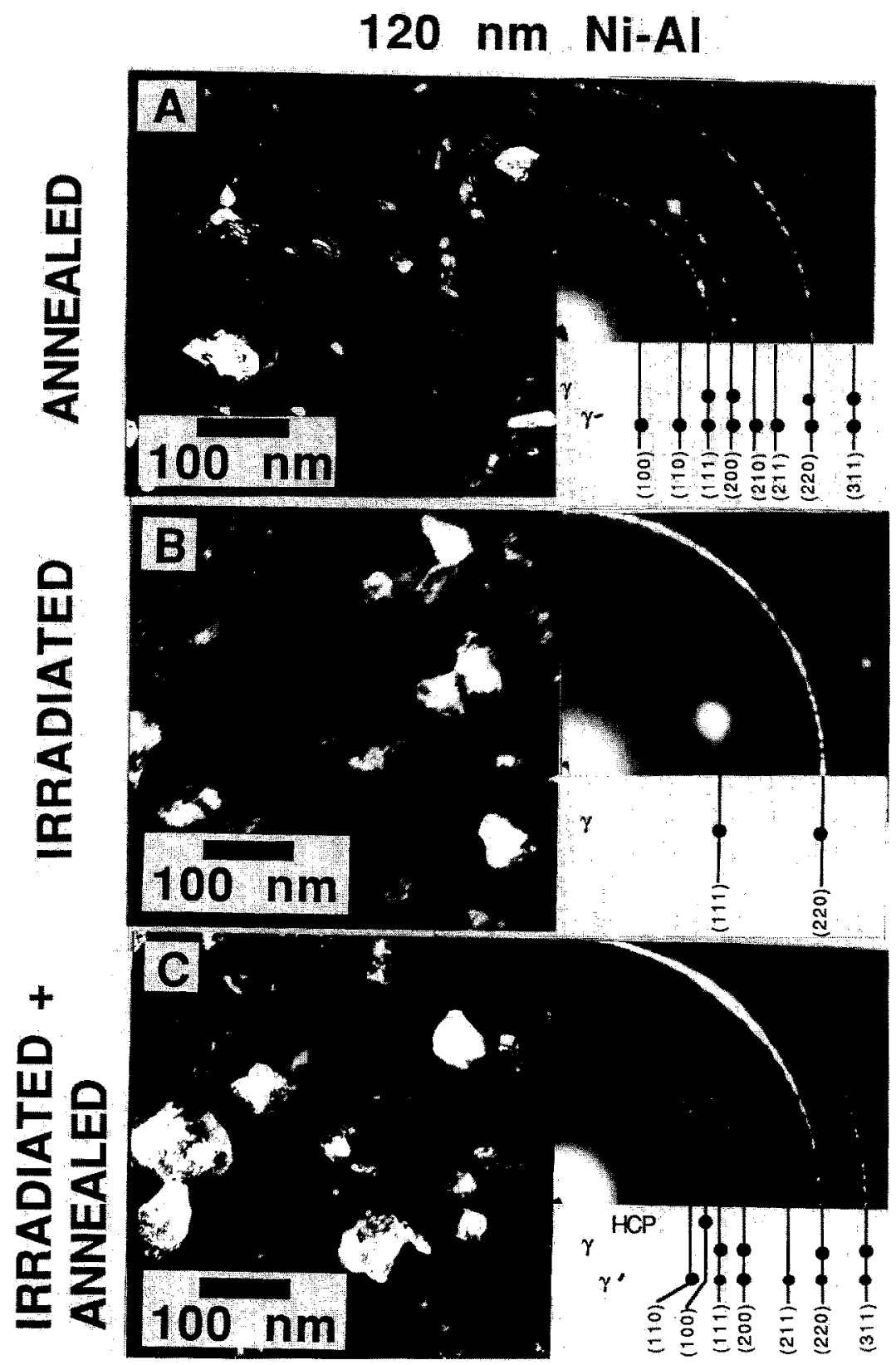

Fig. 1. Dark field images of microstructures and corresponding selected area electron diffraction patterns for treatments performed


$\mathrm{Ni}^{+}$as in (B) then annealed as in (A). Dark field imaged using reflections from the 220 ring.

Irradiation of the $120 \mathrm{~nm}$ multilayers produced a nonequilibrium supersaturated solid solution of $\gamma$, fig. 1b. The SAD pattern shows a strong reflection from the (220) planes with a (111) ring partially discernible. No $\gamma^{\prime}$ rings are evident. The SAD pattern shown was photographed after tilting to display the entire (220) ring. Prior to tilting, considerable texture was observed in the (220) ring in the same direction as the (111) $\mathrm{Ni}$ substrate spots in the pattern. This texture indicates an alignment of the $\gamma$ grains in the film with the substrate grains. Another possible explanation of the observed texture is found in the work of Van Wyk et al. [9] in which a strong (110) texture was seen in ion bombarded $\mathrm{Cu}$ films. They suggested that fcc crystallites oriented 

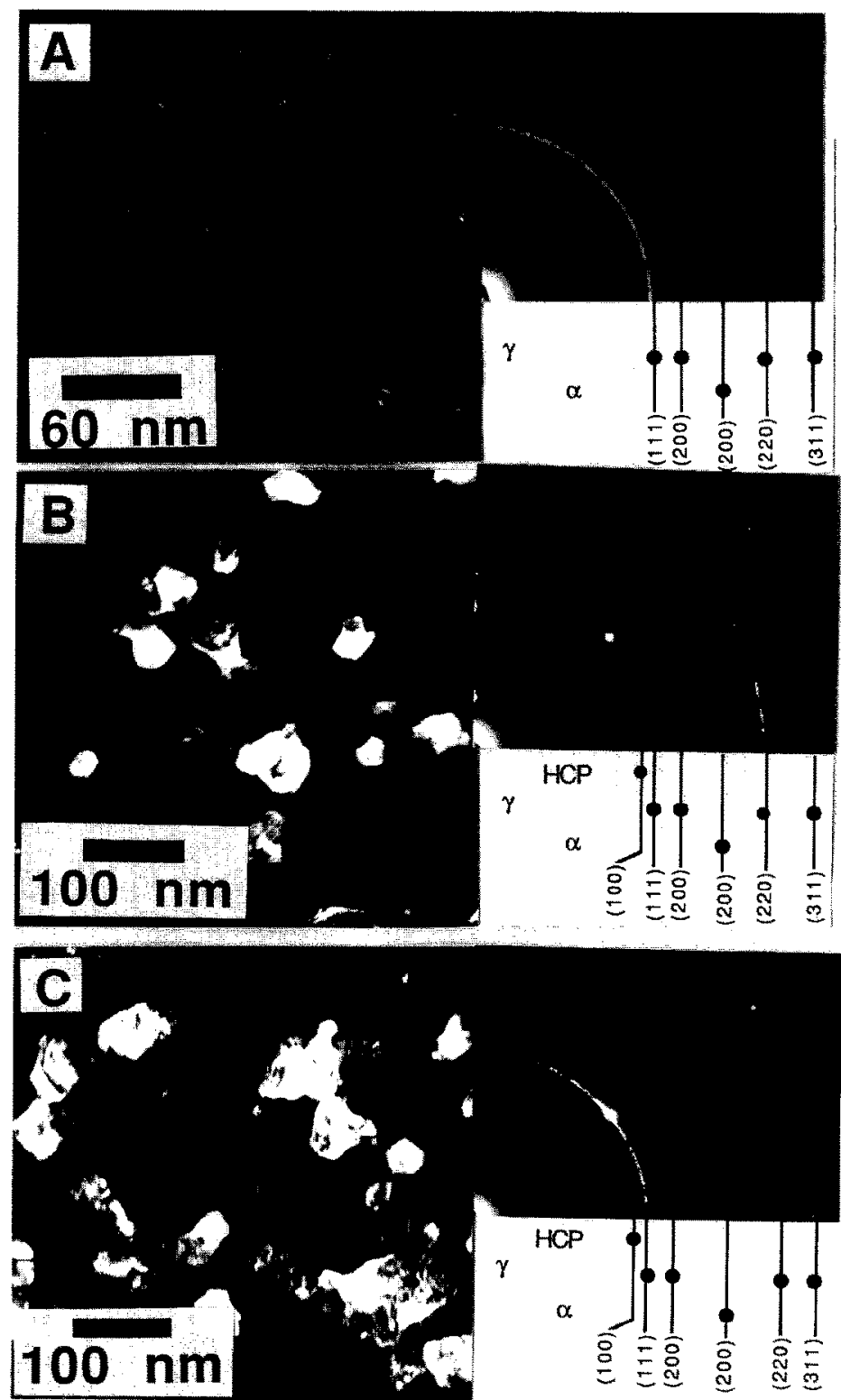

Fig. 2. Dark field images of microstructures and corresponding selected area electron diffraction patterns for treatments performed on $60 \mathrm{~nm} \mathrm{Ni}-20 \mathrm{Cr}-10 \mathrm{Al}$ : (A) annealed at $710 \mathrm{~K}$ for one hour (note the change of scale), (B) irradiated with $350 \mathrm{kev} \mathrm{Ni}^{+}$to $4 \times 10^{16}$ ions $/ \mathrm{cm}^{2},(\mathrm{C})$ irradiated with $\mathrm{Ni}^{+}$as in $(\mathrm{B})$ then annealed as in $(\mathrm{A})$. Dark field imaged using reflections from the (220) ring.

with the [110] direction parallel to the incident radiation suffer less damage (since the $(110)$ plane has a lower atomic areal density compared to other crystallographic planes), and in turn the crystallites act as nucleation sites for other highly damaged grains.

Irradiation combined with post-irradiation annealing of the $120 \mathrm{~nm}$ samples produced the $\gamma^{\prime}$ phase as evidenced by the presence of both the (110) and the (211) $\gamma^{\prime}$ rings in the SAD pattern, fig. 1c. Texture is also apparent particularly in the (220) and (311) rings. Just inside the $\gamma(111)$ ring is the (100) ring belonging to an HCP phase. This phase has been observed to occur in nickel rich $\mathrm{Ni}-\mathrm{Al}$ after threshold irradiation at room temperature [10] and in $\mathrm{Al}^{+}$implantation into nickel [11]. The HCP phase is strongly textured with basal planes parallel to the plane of the film. This is evidenced by the absence of rings resulting from basal plane reflections in the SAD pattern in fig. 1c. Although 


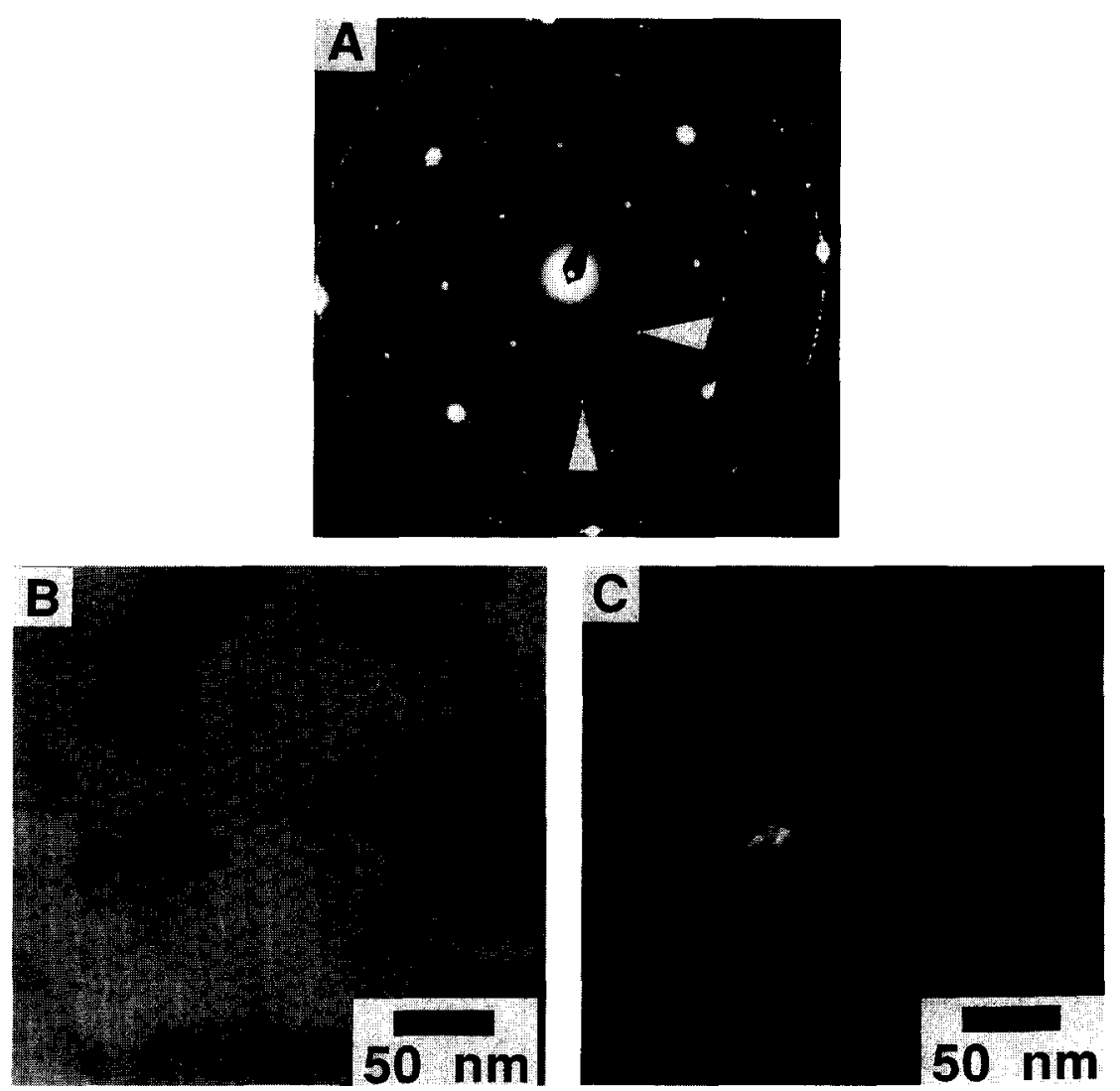

Fig. 3. (A) selected area diffraction pattern for annealed $60 \mathrm{~nm} \mathrm{Ni-21Al} \mathrm{sample} \mathrm{showing} \mathrm{the} \mathrm{presence} \mathrm{of} \mathrm{superlattice} \mathrm{reflections} \mathrm{as}$ indicated by the arrows. (B) Bright field image of the are giving rise to diffraction in (A). (c) Dark field image of small $\gamma^{\prime}$ grains in (B) imaged using the (110) superlattice reflection identified by the bottom arrow in (A).

not evident in the diffraction patterns of fig. $1 \mathrm{~b}$, it is likely that the hcp phase was also present after irradiation of the multilayers as observed by others [10].

Annealing of the $60 \mathrm{~nm} \mathrm{Ni-Cr-Al} \mathrm{samples} \mathrm{at} 710 \mathrm{~K}$ for one hour produced no change in the SAD pattern, fig. 2a, which appears to be identical to the asevaporated case. The composition of this sample is such that it should lie in the two phase $\gamma+\gamma^{\prime}$ region of the equilibrium ternary phase diagram [12]. Assuming homogenization and equilibrium were achieved as in the $120 \mathrm{~nm} \mathrm{Ni}-\mathrm{Al}$ samples, $\gamma^{\prime}$ lines should be evident, but clearly are not. Further, the $\mathrm{Cr}$ ( $\alpha$ phase) (200) ring remains.

The SAD pattern for the irradiated $\mathrm{Ni}-\mathrm{Cr}-\mathrm{Al}$ samples shows rings corresponding to the $\gamma$ phase and the HCP phase, fig. 2b, similar to irradiated Ni-Al, Fig. $1 \mathrm{~b}$. In addition the $\mathrm{Cr}(200)$ ring is still faintly present and has a slight texture corresponding to the texture of the $\gamma(220)$ ring. The (111) ring also exhibits texture in the same direction as the $\mathrm{Ni}$ (111) substrate spots.

Annealing of the irradiated samples produced an SAD pattern, fig. $2 c$, which looks nearly identical to the as-irradiated case. Again, in addition to the $\gamma$ phase, the presence of the HCP and $\mathrm{Cr}-\alpha$ phases are also evident. The $\gamma$ (111) ring displays texture in the direction of the (111) substrate spots.

It should be noted that composition of the $\mathrm{Ni}-\mathrm{Cr}-\mathrm{Al}$ samples were not verified quantitatively. Thus, uncertainty about composition precludes definitive statements about phase formation in these samples. However, the persistence of the $\mathrm{Cr}-\alpha$ phase throughout all treatments is indeed puzzling and requires further study.

One final point warrants some discussion. A region of the film in the $60 \mathrm{~nm} \mathrm{Ni-21Al} \mathrm{sample} \mathrm{was} \mathrm{observed}$ in SAD to show reflections corresponding to superlattice spots in addition to superlattice rings, fig. $3 \mathrm{a}$. Dark field imaging performed on a $\gamma^{\prime}$ (110) superlattice spot showed that the reflection was coming from grains approximately $20 \mathrm{~nm}$ in size, fig. $3 \mathrm{c}$. Although more extensive dark field imaging of the $\gamma^{\prime}$ is needed, this observation suggests that the $\gamma^{\prime}$ in the film is of a smaller grain size than the $\gamma$ grains and thus might explain the nonuniform grain size observed for annealed $\mathrm{Ni}-\mathrm{Al}$ samples. The spotty appearance of $\gamma$ rings versus the fine structure of the $\gamma^{\prime}$ rings in these annealed samples further supports this suggestion. 


\section{Conclusions}

Substantial ion induced grain growth was observed in all samples irradiated with $350 \mathrm{keV} \mathrm{Ni}{ }^{+}$ions to a dose of $4 \times 10^{16}$ ions $/ \mathrm{cm}^{2}$. Grain sizes increased typically by a factor of 7 over the as-evaporated grain size. Thermal annealing of multilayers at $710 \mathrm{~K}$ for one hour produced only a 3-4 fold increase in grain size for the $\mathrm{Ni}-\mathrm{Al}$ samples, and no observable growth in the $\mathrm{Ni}-\mathrm{Cr}-\mathrm{Al}$ samples. Further, considerable nonuniformity was observed in grain sizes for the annealed samples in contrast to the uniform sizes of the irradiated ones. Post-irradiation annealing resulted in minimal grain growth in all samples. The ultimate grain sizes achieved in the $60 \mathrm{~nm}$ thick films compared with the $120 \mathrm{~nm}$ films were nearly the same. This indicated that film thickness effects were not limiting the achievable grain size to a dose of $4 \times 10^{16}$ ions $/ \mathrm{cm}^{2}$. Further work is underway to examine dose variations on grain size for both the $\mathrm{Ni}-\mathrm{Al}$ and $\mathrm{Ni}-\mathrm{Cr}-\mathrm{Al}$ systems.

Annealing of multilayers resulted in the formation of $\gamma$ and $\gamma^{\prime}$ equilibrium phases. Ion irradiation resulted in a supersaturated solid solution of $\gamma$ phase and probably the HCP phase. Considerable texture arose in all the irradiated samples in which the film grains tended to align with the substrate grains. Post-irradiation annealing caused $\gamma^{\prime}$ to form but failed to remove the HCP phase.

Analysis of the phases in the $\mathrm{Ni}-\mathrm{Cr}-\mathrm{Al}$ samples indicated that gamma prime failed to form in all treatments even though the composition was clearly within the 2 phase $\gamma+\gamma^{\prime}$ region of the ternary phase diagram. The HCP phase was formed following irradiation or irradiation + annealing treatments. The $\mathrm{Cr}-\alpha$ phase was present after all treatments.
The authors gratefully acknowledge the staff and the use of the facilities at the Michigan Ion Beam Laboratory for Surface Modification and Analysis at the University of Michigan, as well as the support of $D$. Alexander by the DOE Nuclear Engineering, Health Physics and Radioactive Waste Management Fellowship Program. This work was funded by the national Science Foundation under grant \# DMR8603174.

\section{References}

[1] J.M. Eridon, G.S. Was and L. Rehn, J. Appl. Phys. 62 (1987) 2145.

[2] J.P. Biersack and L.G. Haggmark, Nucl. Instr. and Meth. $174(1980) 257$.

[3] H.T.G. Hentzell, B. Andersson and S.E. Karlsson, Acta Metall. 31 (1983) 2103.

[4] J.C. Liu and J.W. Mayer, Nucl. Instr. and Meth. B19/20 (1987) 538

[5] P. Wissman, Thin Solid Films 6 (1970) R67.

[6] A. Gangulee, S. Krongelb and G. Das, Thin Solid Films 24 (1974) 273.

[7] A. Gangulee, J. Appl. Phys. 45 (1974) 3749.

[8] W.W. Mullins, Acta Metall. 6 (1958) 414.

[9] G.N. Van Wyk and H.J. Smith, Nucl. Instr. and Meth. 170 (1980) 433.

[10] J.M. Eridon, G.S. Was and L. Rehn, J. Mater. Res. 3(4) (1988) 626.

[11] M. Ahmed and D.I. Potter, Acta Metall. 33 (1985) 2221.

[12] A. Taylor and R.W. Floyd, J. Institute of Metals 81 (1952) 451. 